\title{
PERTANGGUNG JAWABAN PERATURAN STANDAR AKUNTANSI KEUANGAN NOMOR 45 TERHADAP LAPORAN KEUANGAN PROGRAM KERJA BADAN MUSYAWARAH KELUARGA MINANG KABAU
}

\section{RESPONSIBILITIES OF REGULATION OF THE FINANCIAL ACCOUNTING STANDARD NUMBER 45 TO FINANCIAL STATEMENTS WORK PROGRAM OF MUSYAWARAH KELUARGA MINANG KABAU}

\author{
Rika Fitri Ramayani \\ Sekolah Tinggi Ilmu Ekonomi Prabumulih \\ rika.fitriypp@gmail.com
}

\begin{abstract}
The situation and characteristics of the Minangkabau Family Consultative Body of the South Sumatra Province have work programs or activities. This appears related to the management of financial statements. This research in the research design used is descriptive qualitative approach. The purpose of using qualitative research methods is to disclose comparatively and in accounting for financial statements in accordance with the guideline PSAK No. 45. The results showed the weekly general cash report or transactions recorded manually in large books, and became the basis for making the budget realization report for the current year. Application of PSAK No. 45, will produce financial reports consisting of: Statements of Financial Position, Activity Reports, Cash Flow Statements and Notes to Financial Statements. The report has been presented in accordance with PSAK No. 45 of 2011. Conclusion, this standard looks more complicated but by applying this standard will produce more adequate financial statements.
\end{abstract}

Keywords: PSAK Guideline Number 45, Financial Statements, Minang Kabau Family Consultative Body

\begin{abstract}
ABSTRAK
Keadaan dan krakteristik Badan Musyawarah Keluarga Minangkabau Provinsi Sumatera Selatan memiliki program-program kerja atau kegiatan. Hal tersebut muncul keterkaitan dengan manajemen laporan keuangan. Penelitian ini di rancangan penelitian yang digunakan adalah deskriptif kualitatif dengan melakukan pendekatan. Tujuan menggunakan metode penelitian kualitatif untuk menggungkapkan secara komperatif dan secara akuntansi terhadap laporan keuangan sesuai peraturan pedoman PSAK Nomor 45. Hasil penelitian menunjukkan laporan kas umum setiap minggunya atau transaksinya di catat secara manual dibuku besar, dan menjadi dasar pembuatan laporan realisasi anggaran untuk tahun berjalan. Penerapan PSAK No. 45, akan menghasilkan laporan keuangan yang terdiri atas: Laporan Posisi Keuangan, Laporan Aktivitas, Laporan Arus Kas dan Catatan atas Laporan Keuangan. Laporan tersebut sudah di sajikan sesuai PSAK Nomor 45 Tahun 2011. Simpulan, standar ini terlihat lebih rumit tapi dengan menerapkan standar ini akan menghasilkan laporan keuangan yang lebih memadai.
\end{abstract}

Kata Kunci: Pedoman PSAK Nomor 45, Laporan Keuangan, Badan Musyawarah Keluarga Minang Kabau 


\section{PENDAHULUAN}

Badan Musyawarah Keluarga Minangkabau Provinsi Sumatera Selatan merupakan organisasi berbentuk sosial kemasyarakatan dalam bentuk kesatuan masyarakat Miangkabau di perantauan khususnya di Sumatera Selatan. Bahwa untuk kelancaran kerja dan kegiatan perlu ada keterlibatan pemerintah yang bertanggung jawab. Badan Musyawarah Keluarga Minangkabau Provinsi Sumatera Selatan dibawah tanggung jawab Gebenur Sumatera Selatan. Mengaju pada Undang-undang Nomor 17 Tahun 2013 tentang organisasi kemasyarakatan dan keputusan Gebenur Provinsi Sumatera Selatan Nomor 145/KPTS/BAN.KBP/2016 tentang perubahan atas keputusan Gebenur Provinsi Sumatera Selatan Nomor 865/KPTS/BAN.KBP/2016 tentang pembentukan forum pembauran kebangsaan Provinsi Sumatera Selatan (Wibisono 2009).

Keadaan dan krakteristik Badan Musyawarah Keluarga Minangkabau Provinsi Sumatera Selatan memiliki program-program kerja atau kegiatan. Hal tersebut muncul keterkaitan dengan manajemen laporan keuangan. Mengingat pentingnya laporan keuangan bisa pertanggung jawaban terhadap manajemen laporan keuangan sesuai pedoman pelaporan keuangan terhadap Peraturan Standar Akuntansi atau PSAK Nomor 45 tahun 2011 mengenai pelaporan keuangan entitas nirlaba. Dikaitkan antara sistem pelaporan keuangan, pertanggung jawaban, kinerja keuangan terhadap manajemen keuangan pada laporan posisi keuangan, tujaun laporan posisi keuangan, klasifikasi aset, arus kas dan pemberian informasi jasa

Dalam defenisi Jumingan (2006), laporan keuangan merupakan hasil refleksi dari sekian banyak transaksi yang terjadi dalam suatu perusahaan, sekaligus merupakan hasil tindakan pembuatan ringkasan data keuangan perusahaa. Lantas laporan keuangan disusun dan ditafsirkan untuk kepentingan manajemen dan pihak lain yang menaruh perhatian atau mempunyai kepentingan dengan data keuangan perusahaan.

Menurut Ikatan Akuntansi Indonesia (2002), mendefenisikan laporan keuangan sebagai berikut: laporan keuangan merupakan bagian dari proses pelaporan keuangan. Laporan keuangan biasa meliputi neraca, laporan rugi / laba, laporan perubahan posisi keuangan, catatan dan laporan lain serta materi penjelasan yang merupakan bagian dari laporan keuangan.

Organisasi nirlaba adalah suatu institusi yang menjalankan tidak berorientasi mencari laba yang bersasaran pokok untuk mendukung perihal di dalam menarik perhatian publik untuk suatu tujuan yang tidak komersil. Mardiasmo (2009). Karakteristik organisasi Nirlaba terdiri dari :

1. Sumber daya organisasi berasal dari para penyumbang yang tidak mengharapkan pembayran kembali atau manfaat ekonomi yang sebanding dengan jumlah sumber daya yang diberikan.

2. Menghasilkan baran dan jasa tanpa bertujuan menumpuk laba, dan jika suatu organisasi menghasilkanlaba, maka jumlah tidak pernah dibagikan kepada para pendiri atau pemilik organisasi tersebut.

3. Tidak ada kepemilikan seperti izin pada organisasi bisnis, dalam arti bahwa kepimilikan dalam organisasi nirlaba tidak dijual, diahlikan atau ditebus kembali atau kepemilikan tersebut tidka mencermin proposi pembagian sumber daya organisasi pada saat likuidasi atau pembubaran organisasi. 
Standar akuntansi merupakn pedoman untuk melakukan pratik akuntansi yang didalamnya materi mencakup semua aspek yang terkait dengan akuntansi, yang dalam penyusunan melibatkan kemampuan dari sekumpulan orang yang tergabung dalam suatu lembanga. (Gade 2002).

Sekumpulan orang tergabung tergabung dalam suatu lembanga dinamakan Ikatan Akuntansi Indonesia (IAI) yang sebagai buku petunjuk bagi pelaku akuntansi yang berisi pedoman tentang segala hal yang ada hubungan dengan akuntansi. Pernyataan Standar Akuntansi adalah suatu kemulutan bagi setiap perusahaan dalam membuat laporan keuangan.

Ikatan Akuntansi Indonesia (IAI) menerbitkan Pernyataan Standar Akuntansi Keuangan Nomor 45 Tahun 2011 merupakan standar khusus organisasi nirlaba. Dalam pelaksanaan pengelolaan keuangan satu organisasi nirlaba dapat memperoleh suatu surplus yang merupakan selisih antara kas masuk dengan aliran kas keluar. Organisasi nirlaba pada umum nya memiliki pemimpin, pengurus atau pertanggung jawaban yang menerima amanat dari para stakeholder, terkait dengan konsep akuntabilitas.

Badan menurut Poerwadarmita (2005) adalah sekumpulan orang yang merupakan kesatuan untuk mengerjakan sesuatu. Penilitian ini dilakukan terhadap suku minangkabau yang merantau tersebar di Provinsi Sumatera Selatan. Suku Bangsa Minangkabau adalah salah satu suku bangsa yang mendiami Indonesia. Suku bangsa Minagkabau berasal dari Sumatera Barat dan terkenal keunikan anekaragaman dan adat istiadat yang dimiliki. Salah satunya sistem kekerabatan matrilieal yang mereka anut.

$$
\text { Badan Musyawarah Keluarga }
$$

Minangkabau (BMKM) Provinsi

Sumatera Selatan adalah organisasi berbentuk sosial kemasyarakatan dalam bentuk kesatuan masyarakat Minagkabau di prantauan khusus di Provinsi Sumatera Selatan. Kelancaran organisasi perlu ditetapkan surat keputusan penggurusan Badan Musyawarah Keluarga Minagkabau (BMKM)

Provinsi Sumatera Selatan sesuai anggaran dasar Badan Musyawarah Keluarga Minangkabau (BMKM) Provinsi Sumatera Selatan SK Nomor 04/MB/BMKM-SUMSEL/XII/2014.

\section{METODE PENELITIAN \\ Desain dan Metode Analisis}

Desain penelitian yang digunakan adalah deskriptif kualitatif dengan melakukan pendekatan. Tujuan menggunakan metode penelitian kualitatif untuk menggungkapkan secara komperatif terhadap berapa besar pengaruh PSAK Nomor 45 Tahun 2011 terhadap laporan keuangan Badan Musyawarah Keluarga Minangkabau Provinsi Sumatera Selatan.

Sedangkan metode analisis yang digunakan adalah metode deskripif, yaitu menemukan fakta dan melukiskan secara akurat sifat fenomena baik secara kelompok atau individu. Hal ini dimaksudkan untuk melakukan keseragaman dalam penyajian laporan keuangan sesuai peraturan pemerintah yang telah ditetapkan terhadap pedoman akuntansi organisasi nirlaba.

Data yang digunakan dalam penelitian nantinya meliputi fakta dan informasi menyakut pengaruhnya akuntansi penyajian laporan keuangan.

1. Data primer adalah data berasal dari wawancara dan pengamatan yang menghasilkan data, serta perkataan informan yang ada hubungannya dengan objek permasalahan yang teliti. Data primer diperoleh staff keuangan. 
2. Data sekunder adalah data yang diperoleh atau dikumpulkan dari sumber-sumber yang ada. Dalam penelitian ini yang berasal laporan keuangan, Asset, kewajiban, aktivitas dan arus kas diambil periode tahun 2014- tahun 2017 dalam program kerja di Badan Musyawarah Keluarga Minangkabau Provinsi Sumatera Selatan.

\section{Populasi dan Sampel}

Populasi adalah suatu himpunan unit yang biasanya berupa orang, objek, transaksi atau kejadian dimana kita tertarik untuk mempelajarinya (Kuncoro, 2001). Populasi dalam penelitian staff keuangan di Badan Musyawarah Keluarga Minangkabau Provinsi Sumatera Selatan. Sampel adalah kriteria untuk pemilihan sampel yanga akan teliti dalam penelitian ini adalah laporan keuangan, asset, yang diambil periode Desember 2011Desember 2013.

\section{Definisi Operasional Variabel}

Agar penelitian ini dapat dilaksanakan sesuai dengan yang diharapkan, maka perlu dipahami berbagai unsur-unsur yang menjadi dasar dari suatu penelitian ilmiah yang termuat dalam operasional variabel penelitian.

\section{Tabel 1 Tabel Operasional Variabel}

\begin{tabular}{|c|c|}
\hline \multirow{2}{*}{ Variabel dan Defenisi } & Indikator \\
\hline & PSAK Nomor 45 \\
\hline \multirow{2}{*}{\multicolumn{2}{|c|}{$\begin{array}{l}\text { Defenisi dari Ikatan } \\
\text { Akuntansi Indonesia }\end{array}$}} \\
\hline & \\
\hline \multirow{2}{*}{$\begin{array}{lr}\text { menerbitkan } & \text { Pernyataan } \\
\text { Standar } & \text { Akuntansi }\end{array}$} & \\
\hline & \\
\hline \multicolumn{2}{|l|}{ Keuangan Nomor 45 Tahun } \\
\hline \\
\hline \multicolumn{2}{|l|}{ khusus organisasi nirlaba. } \\
\hline \multicolumn{2}{|l|}{ Dalam pelaksanaan } \\
\hline \multicolumn{2}{|l|}{ pengelolaan keuangan satu } \\
\hline \multirow{2}{*}{\multicolumn{2}{|c|}{$\begin{array}{l}\text { organisasi nirlaba dapat } \\
\text { memperoleh suatu surplus }\end{array}$}} \\
\hline & \\
\hline \multicolumn{2}{|l|}{ yang merupakan selisih } \\
\hline \multicolumn{2}{|l|}{$\begin{array}{l}\text { antara kas masuk dengan } \\
\text { aliran kas keluar. }\end{array}$} \\
\hline
\end{tabular}

\begin{tabular}{|c|c|c|}
\hline $\begin{array}{l}\text { Laporan keuangan } \\
\text { Defenisi merupakan hasil } \\
\text { refleksi dari sekian banyak } \\
\text { transaksi yang terjadi dalam } \\
\text { suatu perusahaan, sekaligus } \\
\text { merupkaan hasil tindakan } \\
\text { pembuatan ringkasan data } \\
\text { keuangan perusahaan. } \\
\text { Jumigan (2006) }\end{array}$ & 2. & $\begin{array}{l}\text { Laporan } \\
\text { posisi } \\
\text { keuangan } \\
\text { Laporan } \\
\text { Asset } \\
\text { Laporan } \\
\quad \text { aktivitas } \\
\text { Laporan } \\
\quad \text { Arus } \\
\quad \text { kas } \\
\end{array}$ \\
\hline
\end{tabular}

\section{HASIL DAN PEMBAHASAN}

Hasil Penelitian Keuangan dan Administrasi Keuangan

Keuangan dan administrasi

Keuangan Badan Musyawarah Keluarga Minagkabau (BMKM) Provinsi Sumatera Selatan adalah semua harta kekayaan yang di miliki Badan Musyawarah Keluarga Minagkabau (BMKM) Provinsi Sumatera Selatan atau barang yang di kelola oleh penggurusan yang telah ditetapkan dalam pengurusan Badan Musyawarah Keluarga Minagkabau (BMKM) Provinsi Sumatera Selatan yang di bina oleh dewan pembina dari surat keputusan langsung dari Gebenur Provinsi Sumatera selatan. Sesuai bidang masing-masing membantu pelayanan Badan Musyawarah Keluarga Minagkabau (BMKM) Provinsi Sumatera Selatan yang pada hakekatnya administrasi keuangan wadah para donatur dalam kegiatan bakti sosial, pendidikan, pembanguna mesjid dari bidang dakwah dan agama serta bidang ekonomi dan dana. Keuangan pada Badan Musyawarah Keluarga Minagkabau (BMKM) Provinsi Sumatera Selatan mencatat segala kegiatan pemasukan dan pengeluaran kas keuangan Badan Musyawarah Keluarga Minagkabau (BMKM) Provinsi Sumatera Selatan.

\section{Sistem Pelaporan Keuangan}

Berdasarkan keputusan pengesahan anggaran dasar dan anggran rumah tangga pada Bab VI pasal 16 tentang sumber keuangan dan 
pendanaan, data-data di peroleh dan informasi dari nara sumber bagian keuangan di kantor Keuangan pada Badan Musyawarah Keluarga Minagkabau (BMKM) Provinsi Sumatera Selatan. Penulis dapat merangkum bahwa Keuangan pada Badan Musyawarah Keluarga Minagkabau (BMKM) Provinsi Sumatera Selatan memiliki badan hukum yang sejak di dirikan hingga saat ini.

Keuangan pada Badan Musyawarah Keluarga Minagkabau (BMKM) Provinsi Sumatera Selatan masih mencari sistem pengelolaan dan penataan keuangan yang dapat dipertanggung jawab sepenuhnya. Sesuai perubahan dan informasi terbaru dalam mengelolah keuangan. Secara langsung dari nara sumber untuk laporan keuangan transaksi masih dilakukan manual dengan pencatatan secar manual.

Pendanaan bersumber dari donatur-donatur dalam pendanaan setiap progm kerja Badan Musyawarah Keluarga Minangkabau (BMKM) Provinsi Sumatera Selatan. Dimna setiap laporan keuangan kegiatan yang di ajukan di sajikan secra umum tidak sesuai degngan peraturan Standar Akuntansi Keuangan No.45 Tahun 2011 hanya $35 \%$ di sajikan sesuai peraturan Standar Akuntansi Keuangan No.45 Tahun 2011. (sumber nara sumber laporan keuangan BMKM). Laporan keuangan pada Badan Musyawarah Keluarga Minangkabau (BMKM) Provinsi Sumatera Selatan kebanyakan di lakukan kegiatan sosial masyarakat dan program ke agamaan, seni budaya sering di adakan yang bertujuan bersilatuhrahmi keluarga minangkabau di perantauan.

\section{Pencatatan Laporan Keuangan}

Informasi dan data yang diperoleh, Badan Musyawarah Keluarga Minagkabau Provinsi Sumatera Selatan menyusun laporan keuangan sesuai dengan Tata Dasar dan Peraturan Badan Musyawarah Keluarga Minagkabau Provinsi Sumatera Selatan, hal ini berarti Badan Musyawarah Keluarga Minagkabau Provinsi Sumatera Selatan belum menerapkan penyusunan laporankeuangan yang sesuai dengan format laporan keuangan nirlaba yang ada dalam Pernyataan Standar Akuntansi Nomor 45.Dalam PSAK No.45 dicatat mengenai sumbangan terikat dan sumbangan tidak terikat.

Penyampaian laporan keuangan ada lembaga diatas Badan Musyawarah Keluarga Minagkabau Provinsi Sumatera Selatan yatitu Musyawarah besar 45 Badan Musyawarah Keluarga Minagkabau Provinsi Sumatera Selatan dimana pertanggung jawaban lapoaran keuangan baik ada kegiatan ataupun tidak harus disampaikan perbulannya. Sesuai dengan wawancara dan penelitian yang dilakukan oleh peneliti.

\section{Penyajian Laporan Keuangan}

Tabel 2 Laporan Posisi Keuangan Badan Musyawarah Keluarga Minagkabau Provinsi Sumatera Selatan Laporan Posisi Keuangan

Aset

Kas dan setara kas

Jumlah Aset

Kewajiban dan Aset Bersih

Kewajiban

Aset bersih tidak terikat

Aset bersih terikat

Jumlah Kewajiban dan Aset

Rp. 1.508.329.481

Rp. 1.508.329.481

Rp. $\quad 408.329 .481$

Rp. 1.100 .000 .000 Rp. 1.508.329.481

\section{Penyajian Laporan Aktivitas menurut \\ PSAK No. 45}

Tabel 3 Penyajian Laporan Aktivitas menurut PSAK No. 45 


\begin{tabular}{|c|c|}
\hline \multicolumn{2}{|c|}{$\begin{array}{r}\text { Tanggal 31 Desember } 2018 \\
\text { Pendapatan dan Penghasilan Tidak Terikat : }\end{array}$} \\
\hline Sumbangan & $\begin{array}{l}\text { Kat : } \\
\text { Rp.- }\end{array}$ \\
\hline Jasa Layanan & Rp. 499.041.450,00 \\
\hline Penghasilan dari Investasi & Rp. $\quad 2.075 .000,00$ \\
\hline Lain-lain & Rp. $144.276 .000,00$ \\
\hline $\begin{array}{l}\text { Jumlah Pendapatan dan Penghasilan } \\
\text { Tidak Terikat } \\
\text { Aset Bersih yang Dibebaskan dari } \\
\text { Pembasan (Catatan C). }\end{array}$ & Rp.645.392.450,00 \\
\hline Pemenuhan Program Pembatasan & Rp. $133.994 .750,00$ \\
\hline $\begin{array}{l}\text { Jumlah Aset yang telah } \\
\text { berakhir pembatasannya }\end{array}$ & $\underline{\text { Rp.133.994.750,00 }}$ \\
\hline $\begin{array}{l}\text { Jumlah Pendapatan, Penghasilan } \\
\text { dan Sumbangan Lain } \\
\text { Beban dan Pengeluaran : }\end{array}$ & $\underline{\text { Rp.779.387.200,00 }}$ \\
\hline Setoran ke BUMES BMKM & Rp. 221.622.675,00 \\
\hline Beban Gaji Pengajar mengaji dan ulama & Rp. $331.908 .505,00$ \\
\hline Biaya Umum & Rp. $71.866 .050,00$ \\
\hline Pembinaan & Rp. $91.400 .000,00$ \\
\hline Kontribusi Kegiatan Internal & Rp. 42.594 .750 .00 \\
\hline Kontribusi kegiatan Eksternal & Rp. $\quad 5.050 .000,00$ \\
\hline Jumlah beban & Rp. 825.096.080,00 \\
\hline Penurunan Jumlah Aset Bersih & \\
\hline Tidak Terikat & (Rp. 45.708.880,00) \\
\hline Penurunan Jumlah Aset Bersih & \\
\hline $\begin{array}{l}\text { Tidak Terikat } \\
\text { Pemenuhan Program Pembatasan : }\end{array}$ & (Rp. 45.708.880,00) \\
\hline Sumbangan & Rp. $200.516 .300,00$ \\
\hline Aset Bersih terbebaskan dari pembatasan & (Rp. 133.994.750,00) \\
\hline Kenaikan Aset Bersih Terikat & Rp. 66.521.550,00 \\
\hline Kenaikan Aset Bersih & $\overline{\text { Rp. 20.812.670,00 }}$ \\
\hline Aset Bersih pada Awal Tahun & Rp. $8.468 .465,00$ \\
\hline Aset Bersih pada Akhir Tahun & Rp. 29.281.135,00 \\
\hline
\end{tabular}

\section{Tabel 4 Laporan Arus Kas}

\begin{tabular}{|c|c|}
\hline \multicolumn{2}{|c|}{$\begin{array}{l}\text { Laporan Arus Kas } \\
\text { Untuk Program Kegiatan berakhir tanggal } 31 \text { Desember } 2018 \\
\text { Arus Kas dari Aktivitas Operasi : }\end{array}$} \\
\hline Kas dari pendapatan jasa & Rp. 499.047.450,00 \\
\hline Kas dari penyumbang & Rp. - \\
\hline Penerimaan Lain-lain & Rp. 144.276.000,00 \\
\hline Biaya Umum & (Rp. 71.866.050,00) \\
\hline Biaya Gaji & (Rp. 331.908.505,00) \\
\hline Biaya Lain-lain & (Rp. 152.054.100,00) \\
\hline $\begin{array}{l}\text { Kas bersih yang diterima (digunakan) } \\
\text { untuk aktivitas operasi } \\
\text { Arus Kas dari Aktivitas Investasi : }\end{array}$ & Rp. 87.494.795,00 \\
\hline $\begin{array}{l}\text { Arus Kas dari Aktivitas Investasi : } \\
\text { Penerimaan dari Investasi }\end{array}$ & $\underline{\text { Rp. 2.075.000,00 }}$ \\
\hline $\begin{array}{l}\text { Kas bersih yang diterima (digunakan) } \\
\text { untuk aktivitas Investasi }\end{array}$ & Rp. 2.075.000,00 \\
\hline $\begin{array}{l}\text { Arus Kas dari Aktivitas Pendanaan : } \\
\text { Penerimaan dari kontribusi pengurus }\end{array}$ & intuk : \\
\hline Kemandirian & Rp. 85.801.700,00 \\
\hline Keperuan listrik perbulan & Rp. $1.366 .000,00$ \\
\hline Donatur khusus & Rp. 46.677.400,00 \\
\hline Kegiatan dana dikeluarkan & Rp. 66.671.200,00 \\
\hline Aktivitas Pendanaan Lain : & \\
\hline Setoran ke MUBES BMKM & (Rp. 221.622.675,00) \\
\hline Kontribusi kegiatan Internal & (Rp. $\quad 5.050 .000,00)$ \\
\hline Kontribusi kegiatan Eksternal & (Rp. 42. 594.750,00) \\
\hline $\begin{array}{l}\text { Kas bersih yang diterima (digunakan) } \\
\text { untuk aktivitas Pendanaan }\end{array}$ & $\underline{\text { (Rp. 68.751.125,00) }}$ \\
\hline $\begin{array}{l}\text { Kenaikan (penurunan) bersih dalam } \\
\text { kas dan setara kas }\end{array}$ & Rp. 20.812.670,00 \\
\hline Kas dan setara kas pada awal tahun & Rp. 8.468.465,00 \\
\hline Kas dan setara kas pada akhir tahun & Rp. 29.281.135,00 \\
\hline
\end{tabular}

Sumber: Data Olahan, 2018
Penjelasan dari Laporan Arus Kas berdasarkan Tabel 4 adalah sebagai berikut.

1. Arus Kas dari Aktivitas Operasi. Akun-akun yang disajikan adalah penambahan dan pengurangan arus kas yang terjadi pada perkiraan yang terkait dengan operasional seperti Kas dari Dana pembayaran gaji, Kas dari MUBES, Kas dari pendapatan lainlain.

2. Arus Kas dari Aktivitas Investasi. Dalam Aktivitas Investasi tidak ada saldo karena MUBES tidak melakukan aktivitas investasi

3. Arus Kas dari Aktivitas Pendanaan. Perkiraan yang termasuk dalam aktivitas pendanaan adalah perkiraan penerimaan dari Infaq yang berasal dari donatur-donatur dan bantuan kas pemerintah yang penggunaannya dibatasi untuk pelaksanaan pembangunan fisik kantor Badan Musyawarah Keluarga Minangkabau Provinsi Sumatera Selatan.

Dasar Laporan Penyusunan Akuntansi Laporan dibuat sesuai Pernyataan Standar Akuntansi Keuangan (PSAK) No.45 Revisi 2011tentang pelaporan keuangan untuk entitas nirlaba. Laporan keuangan menurut PSAK 45 akan menyajikan jumlah masing-masing kelompok aset bersih berdasarkan ada tidaknya pembatasan oleh penyumbang, yaitu (1) terikat permanen, (2) terikat temporer dan (3) tidak terikat Pembatasan yang bersifat permanen adalah pembatasan penggunaan sumber daya yang ditetapkan oleh penyumbang agar sumber daya tersebut dipertahankan secara permanen (Nasirudin 2009). Pembatasan yang bersifat temporer adalah pembatasan penggunaan sumber daya oleh penyumbang yang menetapkan sumber daya tersebut dipertahankan untuk periode tertentu 
atau sampai dengan terpenuhinya keadaan tertentu. Metode Arus Kas disusun dengan metode langsung dan mengelompokan arus kas kedalam kelompok aktivitas operasi, investasi dan pendanaan. Kantor Badan Musyawarah Keluarga Minangkabau Provinsi Sumatera Selatan. aktivitasnya menyajikan aset netto terikat dalam Donatur dan sumbagan dalam program kerja yang akan dilaksanakan. Kas infaq, donatur adalah sumbangan yang diperuntukkan untuk membiayai pembangunan fisik pembangunan mesjid, biaya gaji karyawan mengajar mengaji. Jika kebutuhan untuk akun tersebut telah terpenuhi, maka dana tersebut dapat digunakan untuk pembiayaan aktivitas lainnya. Apabila aset netto terikat tersebut tidak cukup membiayai kebutuhan biaya Pembangunan maka kebutuhan dana tersebut dipenuhi dengan sumbangan lainnya.

Pencatatan Laporan Keuagan yang dibuat Badan Musyawarah Keluarga Minagkabau Provinsi Sumatera Selatan berdasarkan arahan pemilik yayasan dan Pemerintah langusng dari Gebenur Sumatera Selatan, Dasar pencatatannya yaitu Bukti penerimaan kas BUMES donatur tetap dan infaq untuk penerimaan dana Yayasan menggunakan slip penarikan dari bank sebagai dasar pencatatan, untuk pengeluaran kas yang menjadi dasar pencatatan ialah kwitansi. Kemudian bukti transaksi ini diinput kedalam Laporan Badan Musyawarah Keluarga Minagkabau Provinsi Sumatera Selatan.

Kemudian akan dipergunakan untuk membuat Laporan keuangan. Realisasi Anggaran untuk tahun berjalan. Badan Musyawarah Keluarga Minagkabau Provinsi Sumatera Selatan juga memiliki daftar inventaris walau hanya mencantumkan nama inventaris dan jumlahnya, tanpa harga perolehan. Masalah yang ditemukan dalam Laporan Keuangan Badan Musyawarah Keluarga Minagkabau Provinsi Sumatera Selatan adalah masalah pengelompokkan transaksi.

Pihak Badan Musyawarah Keluarga Minagkabau Provinsi Sumatera Selatan belum mengelompokkan jenis akun dengan baik, selain itu Badan Musyawarah Keluarga Minagkabau Provinsi Sumatera Selatan belum membuat penyusutan pada inventarisnya. Kemudian masih banyak terdapat salah catat dalam Buku Kas Umumnya. Berdasarkan pada PSAK No. 45, sekilas terlihat lebih rumit dibandingkan dengan laporan keuangan Madrasah, tetapi Laporan Keuangan yang dihasilkan berdasarkan PSAK No.45 ini jelas memberikan hasil yang lebih relevan (Hendrawan 2011), dapat diandalkan dan dapat dibandingkan, karena lebih akurat sehingga akuntabilitas dari laporan keuangan itu sendiri lebih memadai dibandingkan menggunakan laporan keuangan yang dibuat Badan Musyawarah Keluarga Minagkabau Provinsi Sumatera Selatan.

\section{PENUTUP}

Kesimpulan

Laporan keuangan yang dibuat oleh Badan Musyawarah Keluarga Minagkabau Provinsi Sumatera Selatan lebih sederhana, setiap kas masuk yang diperoleh dari Komite dan Dana BUMES akan dicatat kedalam bukti kas setoran yang dipegang oleh pihak terkait yang bertanggungjawab dalam hal tersebut. Selain itu, ketika terjadi transaksi yang menyebabkan kas berkurang juga dibuatkan bukti kas keluar. Bukti kas setoran dan bukti kas keluar ini yang diinput kedalam laporan kas umum setiap minggunya atau transaksinya di catatan secara manual 
dibuku besar, dan menjadi dasar pembuatan laporan realisasi anggaran untuk tahun berjalan. Penerapan PSAK no. 45 pada Badan Musyawarah Keluarga Minangkabau Provinsi Sumatera Selatan. akan menghasilkan laporan keuangan yang terdiri atas: Laporan Posisi Keuangan, Laporan Aktivitas, Laporan Arus Kas dan Catatan atas Laporan Keuangan. Standar ini terlihat lebih rumit tapi dengan menerapkan standar ini akan menghasilkan laporan keuangan yang lebih memadai.

\section{Saran}

Saran yang dapat diberikan penulis, sebagai berikut:

1. Penyusunan Laporan Keuangan sebaiknya berpedoman dan mengikuti ketentuan yang telah ditetapkan oleh Ikatan Akuntan Indonesia yang tertuang dalam Pernyataan Standar Akuntansi Keuangan Nomor 45 Tahun 2011 agar nformasi yang disajikan dalam laporan keuangan lebih jelas, relevan dan memiliki daya banding yang tinggi, selain itu juga agar tujuan dari penyusunan laporan keuangan dapat tercapai dengan maksimal.

2. Badan Pengurus Jemaat melakukan penilaian kembali terhadap asset tetap sehingga tidak lagi dijabarkan jumlah unit tetapi disajikan dalam bentuk harga perolehan atau dalam bentuk nilai buku.

\section{DAFTAR PUSTAKA}

Gade, Muhammad. (2002). Akuntansi Pemerintahan. Jakarta. Fakultas Ekonomi Universitas Indonesia.

Hendrawan, Rony. (2011). Analisis Penerapan PSAK No. 45 Tentang Pelaporan Keuangan Organisasi Nirlaba Pada Rumah Sakit Berstatus Badan Layanan Umum. Skripsi. Fakultas Ekonomi
Universitas

Semarang.

Ikatan Akuntan Indonesia (IAI). (2009). Standar Akuntansi Keuangan revisi. Salemba Empat. Jakarta.

Jumingan. (2006). Analisis Laporan Keuangan. Jakarta: PT. Bumi Aksara.

Kuncoro, Mudrajad. (2009). Metode Riset untuk Bisnis dan Ekonomi. Edisi ketiga. Penerbit Erlangga.Jakarta.

Mardiasmo, (2009). Akuntansi Sektor Publik. Edisi Empat. Penerbit ANDI. Yogyakarta.

Poerwadarminta, W. S. (2005). Kamus Umum Bahasa Indonesia. Jakarta: Balai Pustaka

Nasiruddin. (2009). Evaluasi Penerapan PSAK NO.45 Pada PartaiKeadilan Sejahtera.Skripsi. Universitas Muhammadiyah. Malang.

Wibisono, Nocika Lea. (2009). Penerapan PSAK No. 45 Terhadap Laporan Keuangan Organisasi Nirlaba 